\title{
ANÁLISE DAS INUNDAÇÕES BRUSCAS OCORRIDAS NA REGIÃo SUL do Brasil NO PERÍODO 1980 - 2009
}

\author{
Anderson Spohr Nedel, Tania Saunsen
}

Centro Regional Sul - INPE; Santa Maria, RS

e-mail: asnedel@gmail.com

\section{Resumo}

Desastres naturais são o resultado da interação entre eventos naturais e uma comunidade vulnerável, causando prejuízos humanos, ambientais e materiais. Este estudo tem por objetivo realizar uma análise das inundações bruscas (enxurradas), ocorridas na região Sul do Brasil entre os anos 1980 e 2009. Foram utilizadas as informações de decretos de situação de emergência, obtidas das Coordenadorias Estaduais de Defesa Civil dos estados do Rio Grande do Sul, Santa Catarina e do Paraná, a fim de regionalizar as ocorrências, bem como o período de maior frequência desses eventos. Os resultados mostraram que o estado de Santa Catarina (SC) é o que mais sofre com as enxurradas (974), seguido pelo Rio Grande do Sul (RS), (925) e pelo estado do Paraná (PR), (316). Observou-se também que os episódios mais intensos ocorreram em 1992, no Rio Grande do Sul; em 2008, em Santa Catarina; e em 2009, no Paraná, afetando respectivamente, 174, 167 e 37 municípios. A maioria dos decretos por inundações bruscas se registrou em anos com a presença do fenômeno El Niño, preferencialmente, durante o inverno, no Rio Grande do Sul, em Santa Catarina, durante o verão (fevereiro) e, no Paraná, no período de primavera (mês de outubro). 


\section{Abstract}

Natural disasters are the consequence of natural or anthropogenic events in a specific place or region, affecting people and causing damage to materials, humans, and the environment. This paper aims to analyze the flash floods occurring in the south region of Brazil in the period of 1980 to 2009 . Records of these events were obtained by State Civil Defense Authority to observe the preferential period for these occurrences and the area most affected by events. The results shows that Santa Catarina state is the most affected by flash flood events, followed by Rio Grande do Sul and Paraná states. It was observed also the most intense events occurred in the year 1992, in Rio Grande do Sul, 2008 in Santa Catarina and 2009 in Paraná and affected several cities $(174,167$ and 37 , respectively). The mostly emergency situations by flash flood occurred both El Niño and La Niña periods (years), in the different seasons: winter (Rio Grande do Sul), summer (Santa Catarina) and spring (Paraná).

\section{Introdução}

Desastres naturais (DN) são o resultado da interação entre eventos naturais sobre um sistema vulnerável, acarretando prejuízos de ordem humana, ambiental e material. Os DN podem ser considerados como uma somatória dos processos naturais (PN) ocorridos e da vulnerabilidade (V). Assim, $D N=P N+V$ (Castro, 1998). Dentre os desastres naturais que mais ocorrem na região Sul Brasil, estão as inundações bruscas (enxurradas). A caracterização dessas inundações, segundo a Secretaria Nacional de Defesa Civil - SEDEC - é feita de acordo com sua magnitude (grande, normal ou baixa) e evolução no tempo, podendo ser brusca, gradual, alagamentos e inundações litorâneas. CASTRO (1998) afirma que a inundação brusca (também conhecida como enxurrada) se deve a chuvas concentradas e de grande intensidade, ocorrendo em um intervalo de tempo pequeno após as precipitações. As águas se elevam rapidamente, causando, inclusive, mais mortos do que as inundações graduais, que ocorrem quando as águas sobem e escoam mais lentamente, sendo, portanto, mais previsíveis).

A base de dados internacionais sobre desastres da Universidade de Louvein, Bélgica (EM-DAT), mostra que, no Brasil, nos últimos anos, desastres naturais como inundações, secas, deslizamentos de terras e ondas de frio e calor extremos afetam milhares de pessoas a cada ano, alcançando 
prejuízos da ordem de bilhões de dólares. Eventos extremos de tempo como enxurradas têm castigado principalmente a região Sul do país - Paraná (PR), Santa Catarina (SC) e Rio Grande do Sul (RS) - ocasionando severos danos à sociedade e atingindo milhares de pessoas que têm sofrido com a intensidade e a frequência destes eventos. Ao comparar dados das Coordenadorias Estaduais de Defesa Civil (CEDEC) e Secretarias Estaduais de Defesa civil (SEDEC), o Rio Grande do Sul é o estado que tem sido mais frequentemente atingido por desastres naturais ao longo dos anos. A Figura 1 mostra os decretos de situações de emergência por inundações bruscas, ocorridos entre 1980 a 2009, na Região Sul do Brasil.

O objetivo deste trabalho é quantificar os eventos de inundações bruscas ocorridos na região Sul do Brasil e verificar os períodos mais favoráveis para suas ocorrências, com base em decretos de situação de emergência dos municípios atingidos. Também se busca investigar a associação entre esses episódios e os fenômenos climáticos El Niño e La Niña;

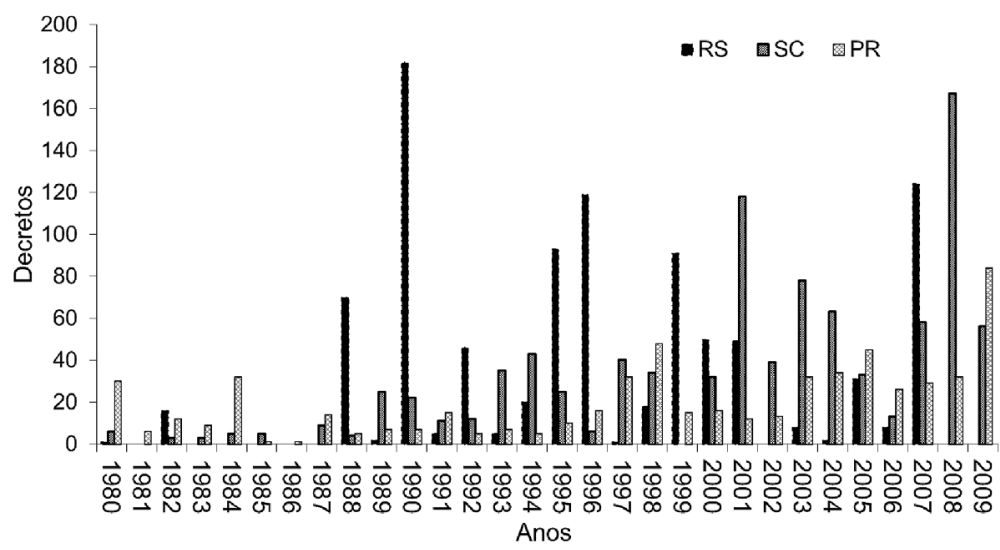

Figura 1. Número de decretos de SE por inundações bruscas no sul do Brasil ao longo dos 29 anos.

\section{Materiais e métodos}

Para este estudo, foram utilizadas informações sobre as ocorrências de eventos de inundações bruscas para o período 1980 a 2009, através de decretos de Situação de Emergência ou Estado de Calamidade Pública dos municípios, obtidas junto às CEDEC e SEDEC dos três estados, que frequentemente são notificadas sobre a ocorrência dessas adversidades. 
Segundo Castro (1998), Situação de Emergência (SE) é o reconhecimento (legal) pelo poder público de uma situação anormal, provocada por desastre, causando danos superáveis (suportáveis) pela comunidade afetada. O Estado de Calamidade Pública também é o reconhecimento legal pelo poder público de situação anormal causada pelos desastres, mas diferencia-se da SE pelo grau de severidade dos danos causados e a incapacidade da comunidade em recuperar-se com recursos próprios. A opção por se empregar dados provenientes das CEDEC foi dada em função da inexistência no Brasil de uma sistematização confiável sobre a ocorrência de inundações bruscas e demais desastres naturais. Além disso, considerou-se que a decretação de SE ou Estado de Calamidade Pública sinaliza a ocorrência de um sinistro significativo que afetou a normalidade naquele município. Cabe salientar que esse é um dos critérios para inserção no banco do EM-DAT.

Quanto a confiabilidade dos dados em relação aos decretos disponíveis pelos estados, Marcelino et al (2006) elaboraram uma comparação entre dados da CEDEC de Santa Catarina e do EM-DAT. Segundo esse estudo, a diferença foi discrepante entre os números totais de desastres naturais das duas fontes. Entretanto, para cada tipo de desastre foi encontrada uma correspondência, entre os dois bancos de dados, com uma correlação de o,87.

Os dados foram organizados em tabelas de acordo com o tipo de evento ocorrido, bem como, a data de sua ocorrência, a fim de se analisarem as frequências mensais e anuais e os períodos mais favoráveis para sua ocorrência. Para caracterizar as frequências do período de início e término de cada estação do ano, adotou-se o seguinte intervalo: Outono (março, abril, maio), Inverno (junho, julho, agosto), Primavera (setembro, outubro, novembro), Verão (dezembro, janeiro, fevereiro).

\section{Resultados e discussão}

A seguir, são apresentadas as frequências de ocorrências e as regiões preferenciais dos eventos de inundações bruscas na região sul do Brasil. A Figura 2 mostra o período de ocorrência das inundações bruscas nos estados do RS, SC e PR de acordo com as estações do ano. Nota-se que os episódios apesentaram diferentes épocas de ocorrências predominando, principalmente, durante os meses de inverno no RS, ao longo do verão em SC e na primavera no estado do PR. 
(a)

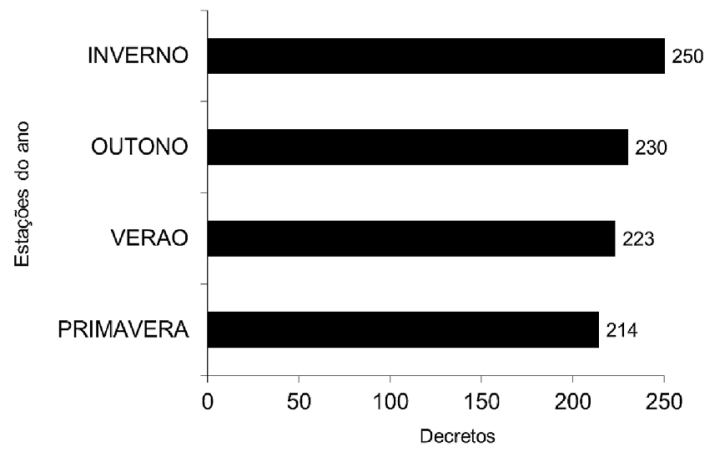

(b)

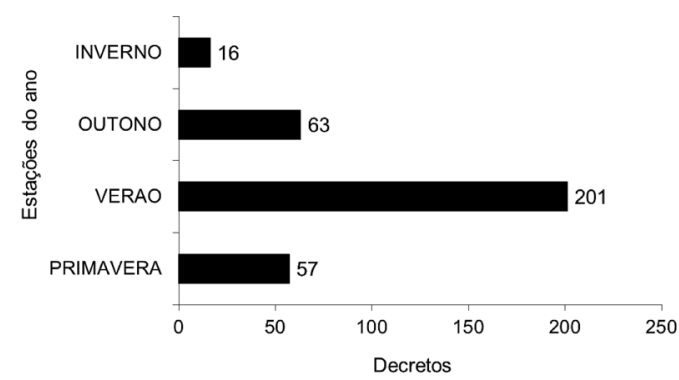

(c)

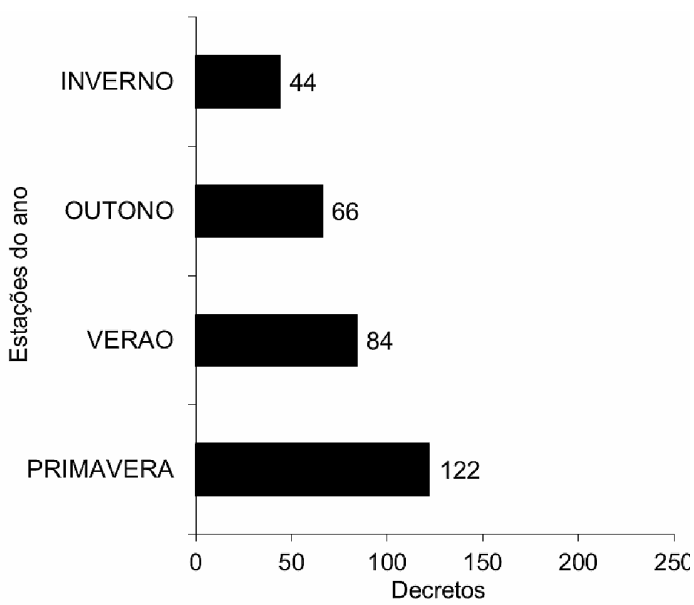

Figura 2. Número de decretos de SE por inundação brusca para as estações do ano nos estados do RS (a), SC (b) e PR (c). 
Para o RS, os meses mais críticos foram junho (160 decretos de $\mathrm{SE})$ e maio (140 decretos de SE), para SC foram os meses de fevereiro (110 decretos de SE) e janeiro (82 decretos de SE) e, para o estado do PR, os meses de outubro (58 decretos de SE) e setembro (37 decretos de SE). É interessante destacar que, no caso do RS, há uma grande diferença entre os decretos registrados nos meses de maio e junho, com os meses seguintes, a partir de julho. Uma explicação para isso seria a influência exercida pelo fenômeno El Niño, que, segundo Berlato e Fontana (2003), apresenta uma re-intensificação, a partir do final do outono (início do inverno) acarretando aumento na frequência das precipitações (aumento de dias de chuva) e, consequente, aumento das inundações bruscas (decretos de SE, Figura 3).

(a)

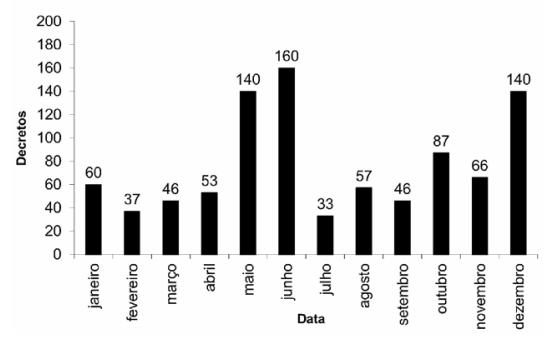

(b)

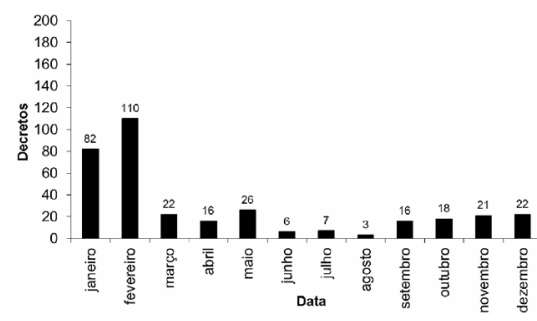

(c)

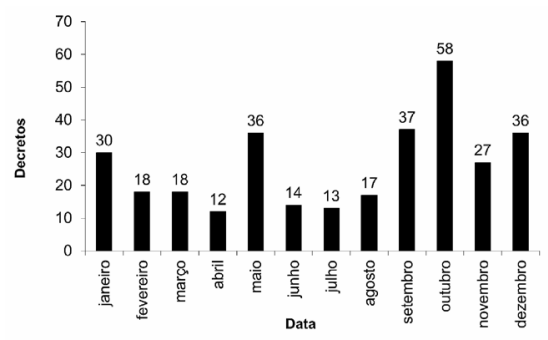

Figura 3. Número de ocorrências mensais de decretos de SE por inundação brusca para os estados do RS (a), SC (b) e PR (c). 
A Figura 4 mostra que o maior número de decretos de SE por inundações ocorreu nos anos 1992 (RS), 2008 (SC) e 2009 (PR). Nos anos de 1992 e 2009, a região Sul do Brasil estava sob influência do fenômeno El Niño (forte e fraco, respectivamente), que provoca chuvas abundantes e acima da média (Grimm et al, 1998). No mês de novembro de 2008 , ocorreram intensas chuvas na região centro-leste de SC, ocasionadas pelo estabelecimento de um bloqueio atmosférico. Segundo informações do Centro de Previsão de Tempo e Estudos Climáticos (CPTEC/INPE), o bloqueio teve associado um intenso anticiclone em superfície sobre oceano atlântico que favoreceu a intensificação dos ventos de quadrante leste e nordeste e a convergência de umidade em superfície sobre a costa leste dos estados de SC e PR. Em altos níveis da atmosfera, existia também a presença de um Vórtice Ciclônico de Altos Níveis - VCAN -, que se estabeleceu entre o sul do Paraná, Santa Catarina e norte do Rio Grande do Sul, o qual promoveu um intenso mecanismo de ascensão das parcelas de ar nestas áreas e foi responsável pelas chuvas intensas observadas no Estado de SC. Cidades como as da região do Vale do Itajaí apresentaram volumes diários de precipitação que ultrapassaram $200 \mathrm{~mm}$, e outras com volumes precipitados em cinco dias maiores que 500mm (CPTEC/INPE, 2009). 
(a)

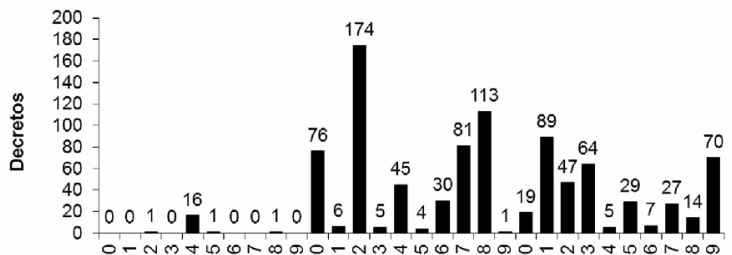

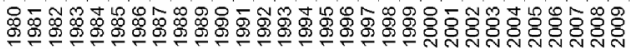

(b)

Data

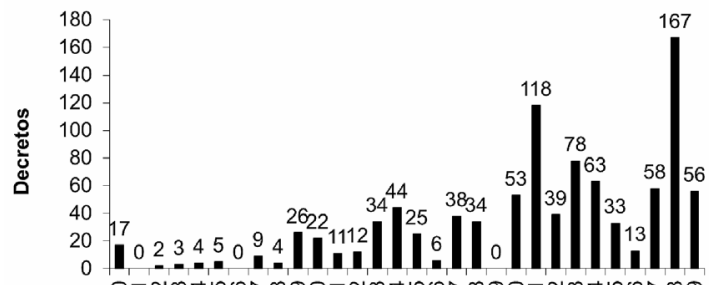

ळ:

(c)

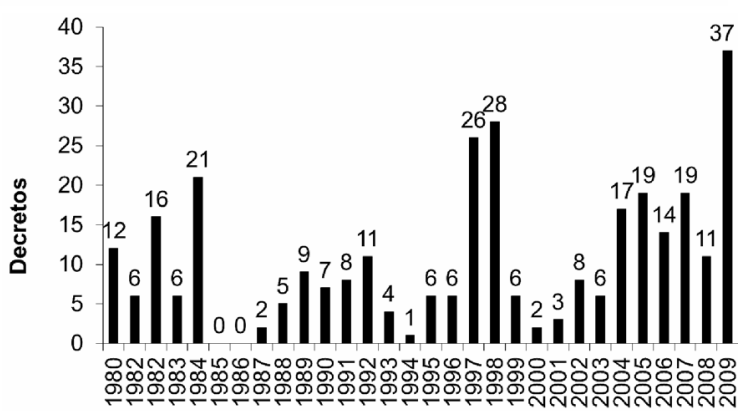

Data

Figura 4. Número anual de decretos de SE por inundação brusca para os estados do RS (a), $\mathrm{SC}$ (b) e PR (c).

Observando todos os 29 anos analisados, ainda na Figura 4, e correlacionando-os com eventos ENOS (El Niño Oscilação Sul), nota-se também que os eventos de inundações bruscas ocorreram alternadamente, em anos de presença dos fenômenos climáticos El Niño, La Niña e em anos considerados como neutros (1990 e 2001, sem a presença dos fenômenos). Entretanto, mesmo que em anos de El Niño a intensidade e frequência de inundações bruscas seja definitivamente maior, não há uma relação direta com os decretos de SE por inundações bruscas, de maneira que apenas exista um aumento no número 
de decretos na presença de um El Niño de intensidade forte. Em outros casos (El Niño, moderado e fraco), esse aumento não se torna evidente, podendo inclusive ocorrer situações de aumento no número de decretos de SE em anos Neutros (2001, RS SC) ou La Niña (2007/2008, RS, SC e PR).

Ao longo do ano de 1992, foram verificados 174 decretos de SE por inundações bruscas no RS. Apenas entre meados de abril a meados de junho desse ano 151 decretos foram reconhecidos pela Defesa Civil do Estado. Segundo Berlato e Fontana (2003), nessa época (entre final do outono/começo do inverno), ocorre um período de "repique" do fenômeno El Niño, ocasionando um novo aumento na intensidade e frequência das chuvas. Para o estado de SC, os decretos de municípios em SE por inundação brusca foram 167, a grande maioria registrada no mês de novembro. Esse ano (2008) começou sob a influência do fenômeno La Niña forte (causando precipitações abaixo da média na região Sul do Brasil, principalmente, nos primeiros meses, Figura 5). Posteriormente, um período de neutralidade térmica se configurou e eventos de frequentes e intensas precipitações com grandes volumes acumulados foram registrados (já comentado anteriormente).
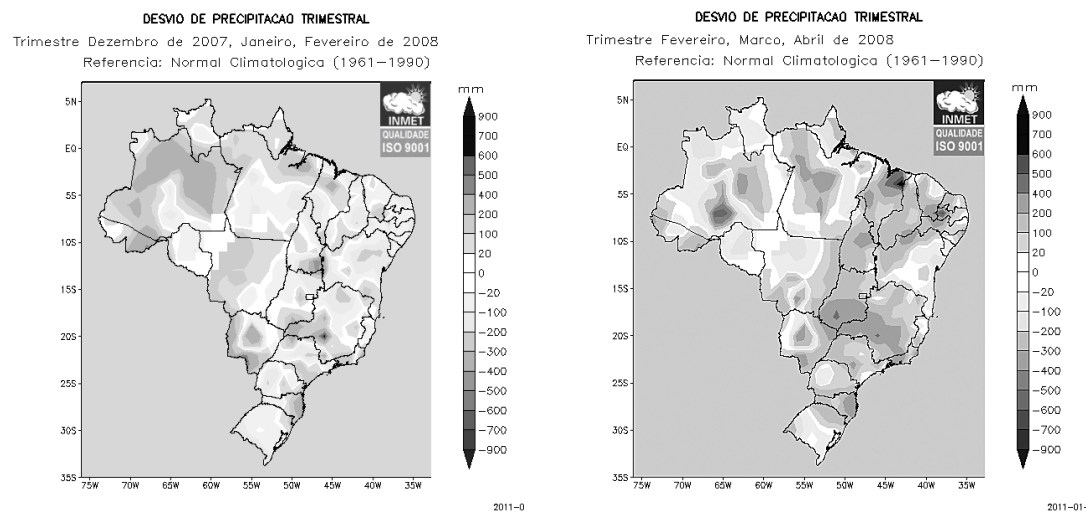

Figura 5. Desvio da precipitação trimestral para o ano de 2008. (a) Janeiro, fevereiro, março; (b) Fevereiro, março, abril.

Para o estado do PR, o ano de 2009 foi aquele com o maior registro de SE por inundações bruscas. Foram 37 decretos de municípios em situação de emergência, nove a mais do que o recorde anterior, observado no ano de 1998 (28 decretos). Nesse período, o Estado sofria a influência do fenômeno El Niño (fraco), 2009-2010, com ocorrência de frequentes precipitações com elevados totais (mensais) acumulados, principalmente entre setembro 
e novembro, quando os volumes das precipitações ultrapassaram em 300 mm a média climatológica (mês de setembro; região central do Estado), segundo registros do Instituto Nacional de Meteorologia (INMET).

Ao separar o período de estudo (1980 a 2009) em décadas, é possível verificar que as inundações bruscas no estado de Santa Catarina e no Paraná foram mais frequentes entre os anos de 2000 e 2009 (681 e 136 decretos, respectivamente). Por outro lado, a década anterior, 1990 a 1999, foi o período de maior registro de decretos no estado do Rio Grande do Sul (535).

\section{Conclusão}

Ao final das análises, pode-se concluir que:

Considerando os 29 anos de dados analisados, dos 2215 decretos de SE registrados pelos municípios da região Sul do Brasil, observou-se que o estado de Santa Catarina é o que mais sofre com esse tipo de desastre (974), seguido pelo Rio Grande do Sul (925) e pelo estado do Paraná (316);

- Os episódios mais intensos (maior número de decretos) ocorreram (ocorreu) ao longo dos anos 1992, no Rio Grande do Sul, 2008 e 2001, em Santa Catarina e em 2009, no Paraná: 174, 167 e 37, respectivamente. No período analisado (1980-2009), observou-se que a maioria dos decretos de SE por inundações bruscas aconteceu em anos com a presença do fenômeno El Niño. Porém, houve episódios com intensas precipitações também em anos considerados como Neutros (2001 e 2008, SC).

- Quando se dividiu o período em três décadas (1980 a 1989; 1990 a 1999; 2000 a 2009), verificou-se que, para o RS, a década de maior impacto foi 1990 a 1999, para o estado de SC e PR, foi a década de 2000 a 2009. Dessa forma, não há como concluir se esses eventos estão aumentando ou não na região Sul do Brasil. Cada estado tem sua peculiaridade em relação aos episódios, ocasionando aumento de decretos de SE em determinado(s) ano(s) e diminuição em outro(s) subsequente(s).

- O período de máxima ocorrência de decretos por inundações bruscas também foi diferenciado nos três estados. No Rio Grande do Sul, estes ocorreram preferencialmente durante o outono (em meados de junho) em SC, durante o verão (fevereiro) no RS, e na primavera (mês de outubro) no PR. Salienta-se, porém, que existe uma defasagem no tempo entre a ocorrência da inundação e a decretação de emergência pelo município afetado. Assim, provavelmente a data do decreto de SE não coincida com o real período de inundação ocorrida. 


\section{Agradecimentos}

Os autores agradecem ao Conselho Nacional de Desenvolvimento Científico e Tecnológico (CNPq), pelo apoio financeiro.

\section{Referências}

BERLATO, M. A.; FONTANA, D. C. El Niño e La Niña: impactos no clima, na vegetação e na agricultura do Rio Grande do Sul; aplicações de previsões climáticas na agricultura. Porto Alegre: UFRGS, 2003. 110 .

CASTRo. A. L. C. Glossário de Defesa Civil: estudos de riscos e medicina de desastres. Brasília: MPO, Departamento de Defesa Civil, 1998, 283p. COORDENADORIA ESTAdUAL DE DEFESA CIVIL Do RIO GRANDE Do SUl (CEDEC). Centro de Operações da Defesa Civil. Disponível em http://www.defesacivil. rs.gov.br. Acesso em 16/01/2010.

COORdenadoria estadual de defESA Civil do paraná (CEDeC). Centro de Operações da Defesa Civil. Disponível em www.defesacivil.pr.gov.br Acesso em $16 / 01 / 2010$.

EM-DAT: The OFDA / CRED International Disaster Database. Universidade Católica de Louvain - Bruxelas, Bélgica. Disponível em http://www.emdat. be Acesso em 28/08/2009.

GRIMM, A M., S. E. T. FERRAZ. ;J. GOMES. Precipitation anomalies in Southern Brazil associated with El Niño and La Niña events. J. Climate. 1998.

INMET, Instituto Nacional de Meteorologia. Disponível em http://www. inmet.gov.br Acesso em 22/02/2010.

MARCELINO, E.V; NUNES, L.H.; коBIYAMA, M. Banco de dados de desastres naturais: análise de dados globais e regionais. Caminhos de Geografia, v. 6, n. 19, outubro de 2006, p. 130-149.

SECRETARIA DE ESTADO DE DEFESA CIVIL DE SANTA CATARINA. Centro de Operações da Defesa Civil. Disponível em http://www.defesacivil.sc.gov.br. Acesso em 16/01/2010.

Submetido em: 20/10/2010

Aceito em: 13/03/2012 